Human Capital and Economic Opportunity: A Global Working Group

Working Paper Series

Working Paper No. 2011-031

\title{
Intrahousehold Distribution and Child Poverty: Theory and Evidence from Côte d'Ivoire
}

Olivier Bargain

Olivier Donni

Prudence Kwenda

October, 2011

Human Capital and Economic Opportunity Working Group Economic Research Center University of Chicago 1126 E. 59th Street 


\title{
Intrahousehold Distribution and Child Poverty: Theory and Evidence from Côte d'Ivoire*
}

\author{
Olivier Bargain, Olivier Donni, Prudence Kwenda
}

September 2011

\begin{abstract}
Poverty measures in developing countries often ignore the distribution of resources within families and the gains from joint consumption. In this paper, we extend the collective model of household consumption to recover mother's, father's and children's shares together with economies of scale, using the observation of adult-specific goods and an extended version of the Rothbarth method. The application on data from Côte d'Ivoire shows that children command a reasonable fraction of household resources, though not enough to avoid a very large extent of child poverty compared to what is found in traditional measures based on per capita expenditure. We find no significant evidence of discrimination against girls, and educated mothers have more command over household resources. Baseline results on children's shares are robust to using alternative identifying assumptions, which consolidates a general approach grounded on a flexible version of the Rothbarth method. Individual measures of poverty show that parents are highly compensated by the scale economies due to joint consumption.
\end{abstract}

Key Words : Collective Model, Consumer Demand, Engel Curves, Rothbarth Method, Cost of Children, Bargaining Power, Sharing rule, Scale Economies, Equivalence Scales, Indifference Scales.

JEL Classification : D11, D12, D36, I31, J12

*Acknowledgements: Bargain is affiliated with Aix-Marseille Université and IZA, Kwenda is affiliated with University College Dublin, Donni is affiliated with the University of Cergy-Pontoise, THEMA and IZA. All errors or omissions remain ours. Corresponding author: O. Donni, Université de Cergy-Pontoise, 33 Boulevard du Port, 95011 Cergy-Pontoise Cedex, France. Email: olivier.donni@u-cergy.fr. 


\section{Introduction}

The ultimate object of concern of redistributive policies is the welfare of individuals while the literature has mainly focused on measuring inequality and poverty among households. In particular, attempts to assess how much of the family resources are dedicated to children, and to evaluate child poverty in this way, are relatively rare. Two well-known problems pertain to the fact that (i) individual allocations within households are rarely observed, and that (ii) welfare measures rarely account for joint consumption in the household. In some occasions, researchers have used anthropometric information (e.g., caloric in-take) to proxy individual nutrition in very low-income countries. This type of research has revealed a very substantial level of intrahousehold inequality (e.g., Haddad and Kanbur, 1990). In more general cases, economists must rely on indirect methods to retrieve the share of household resources commanded by specific individuals and in particular by children. Among the different techniques available, the Rothbarth method (Rothbarth, 1943) is possibly the most theoretically sound approach. As clearly exposed in Gronau $(1988,1991)$, it consists in examining the extent to which the presence of children depresses the household consumption of adult-specific goods. The method has been used in the context of developing countries to measure the cost of children and the extent of gender discrimination among children (see Deaton, 1989, 1997). ${ }^{1}$ A notable drawback of this approach, however, is that it assumes purely private consumption. Obviously, the consumption of some goods is partly joint - or fully joint, in the case of household public goods like housing - and generates economies of scale in multi-person households. This is a central concern in the construction of equivalence scales and the measurement of welfare. In addition, the RothbarthGronau model is not grounded in a microeconomic framework that respects individualism and accounts for the possibly diverging opinions of the parents.

Against this background, the present paper suggests a measure of resource allocation in a multiperson model with economies of scale and parental bargaining. Using data from Côte d'Ivoire, we particularly focus on the share of total expenditure accruing to children and on an original measure of child poverty based on individual resources. The sharing rule and scale economies are identified using an extended version of the Gronau-Rothbarth approach within a structural collective model, i.e., a model that only assumes the efficiency of consumption decisions within the household (Chiappori, 1988).

The approach explicitly deals with the fact that datasets typically contain total purchases at

\footnotetext{
${ }^{1}$ See Gronau $(1989,1991)$ and Lazear and Michael (1988) on the Rothbarth approach. See Browning (1992) for a survey of the various techniques used to measure the cost of children. Note that with this method, the direct utility or disutility from living with others (such as love and companionship) is necessarily assumed to be separable from consumption goods and ignored.
} 
household levels but not the allocation of goods between household members, even when consumption is purely private (as in the case of 'personal goods and services', for instance). Identification relies on the existence of adult goods in the data (adult clothing) and on a simple logic that extends the initial Rothbarth idea. As suggested by Lewbel and Pendakur (2008), an 'independence of base' assumption allows us to simplify the approach, i.e., economies of scale have a pure income effect and the empirical application is reduced to the estimation of a system of Engel curves on cross-sectional data. The outcome of parents' bargaining process is recovered by the use of data on single individuals (the demographic group of reference).

Once the resource shares of adults and children have been estimated, they can be used to compute a direct measure of individual poverty whereby poor persons are not characterized by living in poor households, according to conventional definitions, but are poor because the resources they receive in the household are below some poverty line. In the empirical application, we focus on Côte d'Ivoire, which is the second largest economy in West Africa and a country where almost half the population is poor, i.e., lives on less than $\$ 2$ per day. We also choose this country because it has received much attention in the literature on intrahousehold inequality, so that we can compare traditional results with our novel approach. Due to the quality of the data available and because of some evidence of unequal distribution within households, this country has indeed been the subject of studies by Deaton (1989), Haddad and Hoddinott (1994), Haddad et al. (1994) and many other articles referenced in Deaton (1997).

Our results point to reasonable magnitudes for children's share, from around $13 \%$ of total household expenditure for the first child to a fifth for three children. Shares increase with family size at a decreasing pace, denoting potential economies of scale in child consumption but also the fact that parents are not ready, beyond a certain point, to reduce their own consumption much. Boys receive more than girls but differences are not significant. That is, there is no clear sign of gender discrimination among children as far as expenditure unrelated to health or education are concerned, as also found by Deaton (1989) for the same country or Bhalotra and Attfield (1998) for food allocation among children in Pakistan. ${ }^{2}$ Women seem to command a smaller, yet not significantly different, share of resources compared to their husbands. It turns out that mothers' education improves their own share and their children's share. We find evidence of substantial economies of scale, especially for mothers. ${ }^{3}$ Using resource share estimates, we find a much larger incidence of poverty among children, and lower among adults, compared to measures simply based on per capita expenditures. Originally, we also provide poverty measures adjusted

\footnotetext{
${ }^{2}$ Evidence of gender discrimination is found in Rose (1999) for India and Dunbar et al. (2010) for Malawi. The literature on discrimination in health and education expenditures is vast and beyond the scope of our study.

${ }^{3}$ These terms are not precisely estimated, however, and may, as explained in the paper, capture other dimensions like changes in individual preferences across different household types.
} 
for scale economies. We find that adults in couples, apparently poorer than singles, are in fact greatly compensated by the gains from joint consumption. Our results compare well to those of Dunbar et al. (2010), whose estimates of children's share for Malawi rely on a relatively similar approach. We also provide two variants of our model that focus on children's share and do not make use of data on single individual. The first one ignores distribution among parents and the second additionally ignores scale economies (i.e., the traditional Rothbarth approach). Results tend to consolidate a general approach grounded on the Rothbarth's idea.

The paper is structured as follows. In Section 2, we describe the model and the identification results. In Section 3, we present the functional form, the estimation method and the data. In Section 4, we report and discuss the main results. Additional results and a comparison with the literature are presented in Section 5 while Section 6 concludes.

\section{Related Literature}

The collective model assumes the efficiency of household decisions in a static environment, and posits individual preferences for each household member. The early collective model literature has essentially consisted in testing efficiency (e.g., Browning and Chiappori, 1998). ${ }^{4}$ Several authors have also shown how to identify the slope of the resource sharing function in couples, using price variation, distribution factors (Bourguignon et al., 2009) or exclusive goods in a context where all the consumption is private (e.g., Browning et al., 1994). Retrieving the complete sharing rule has been achieved more recently and at the price of additional assumptions. In particular, some authors have combined data on people living alone and in couples to retrieve individual preferences and hence the sharing function (e.g., Couprie, 2007, Lise and Seitz, 2011, Browning et al., 2008, Lewbel and Pendakur, 2008). They implicitly assume the stability of individual preferences across household types, an assumption acknowledged by Gronau (1988) as a necessary condition to retrieve the various structural components of the model and, in particular, the cost of children. Importantly, none of the contributions listed above explicitly model child welfare or economies of scale. ${ }^{5}$

\footnotetext{
${ }^{4}$ Even this minimalist assumption, that could be justified by the repeated-game context of a family, is not consensual. Tests of efficiency have been rejected in the case of production choices in developing countries (for Côte d'Ivoire, see Duflo and Udry, 2004). More recent studies tend however to restore the efficiency result (see Rangel and Thomas, 2005, for West Africa). Assuming efficiency is also more plausible in the case of - frequently repeated - consumption decisions. Tests of efficiency in consumption are usually not rejected in the literature (see Chiappori and Donni, 2011, for a survey).

${ }^{5}$ The few papers dealing with children in a collective framework actually treat them as public goods for the parents rather than as having their own utility functions (Blundell et al., 2005, Couprie, 2007). An exception is the theoretical paper of Bourguignon (1999), but the author does not consider economies of scale in the
} 
More recently, Browning et al. (2008) and Lewbel and Pendakur (2008) have suggested the identification of multi-utility models with scale economies. In the former study, joint consumption is modeled using (price) transformations à la Barten. Lewbel and Pendakur simplify this approach by assuming the 'independence of base' (IB) assumption for the technology of production, i.e., they suppose that there exists a single function, independent of total expenditure, that scales the expenditure of each individual in the household and represents the economies from joint consumption. Both studies suggest completing identification of the model by exploiting simultaneously data on couples and single-person households. They recover the resource share of each adult and indifference scales (an individual-based concept of equivalence scale, see Lewbel, 2003). These approaches cannot account for couples with children, as children do not live alone. Nonetheless, these studies have inspired recent contributions which address the measure of children's shares in presence of economies of scale in a collective framework. The first one, by Bargain and Donni (2009), focuses on one-child families in France and presents original identification results using information on singles and expenditures on adult goods, together with the IB assumption. The second, by Dunbar et al. (2010), suggests a measure of children's resources in Malawi, using another identification method that requires expenditure on assignable goods (adult male, adult female and child clothing) and semi-parametric restrictions close to the IB condition.

The present paper is easily positioned in this literature. While several studies have estimated systems of Engel curves to retrieve the cost of children or to test for gender discrimination among children, for instance Deaton (1989), Haddad and Hoddinott (1994) or Haddad et al. (1994) for Côte d'Ivoire, we suggest integrating these measures into a more structural framework and allow for more flexibility than the original Rothbarth approach. We extend the identification results of Bargain and Donni (2009) to households with several children and suggest one of the first applications to the measurement of child shares and child poverty in a developing country. ${ }^{6}$ As far as we know, the present paper is also the only attempt to incorporate scale economies and to use indifference scales to reassess individual poverty among adults.

household nor any empirical implementation. Dauphin et al. (2011) suggest a test of collective rationality when three deciders are present in the household, i.e., parents and one child, yet this concerns the specific case of adult children. A recent attempt to identify child costs can be found in Menon and Perali (2007).

${ }^{6}$ The other is the independent contribution of Dunbar et al. (2010), which we extensively compare with our approach in Section 5. Both studies assume that the presence of children can be identified as an income effect that decreases household budget shares on adult goods. 


\section{Theoretical Framework}

\subsection{Collective Decisions, Preferences and Consumption Technology}

We examine household consumption decisions. To begin with, we suppose that there are three types of households. Let $n$ denote the type, with $n=1$ for single adults, $n=2$ for childless couples and $n=3$ for couples with children. Goods are indexed by superscript $k=1, \ldots K$. Individual types are indexed by subscript $i$ and, by convention, we suppose that $i=m$ indicates men, $i=w$ women and $i=c$ children. The log total expenditure in a household is denoted by $x$ and the vector of log prices by $\boldsymbol{p}$.

We first consider the case of a single-person household $(n=1)$. We simply suppose that individual $i(=m$ or $w)$ endowed with log resources $x$ is characterized by a well-behaved (monotonic, strictly quasi-convex, and three times continuously differentiable) indirect utility function, denoted by $v_{i}\left(x, \boldsymbol{p}, \boldsymbol{z}_{i}\right)$, where $\boldsymbol{z}_{i}$ is a vector of individual characteristics (such as age, education, region of residence). Then from the Roy's identity, the budget share of individual $i$ for good $k$ is defined by

$$
w_{i}^{k}\left(x, \boldsymbol{p}, \boldsymbol{z}_{i}\right)=-\frac{\partial v_{i}\left(x, \boldsymbol{p}, \boldsymbol{z}_{i}\right) / \partial p^{k}}{\partial v_{i}\left(x, \boldsymbol{p}, \boldsymbol{z}_{i}\right) / \partial x},
$$

for $i=m$ or $w$ and $k=1, \ldots, K$.

In the case of a multi-person households $(n>1)$, we first suppose that each person living in the household has her/his own indirect utility function. For children, however, we only model the utility of all children and $c$ is an index for the representative child. The main idea is that, after controlling for the existence of joint consumption and the sharing of total expenditure, the utility function of each family member does not depend on the type $n$ of the household. Precisely, the indirect utility function of individual $i=m, w$ or $c$ living in a household of type $n>1$ can be

written as $v_{i}\left(x_{i, n}, \boldsymbol{p}, \boldsymbol{z}_{i}\right)$, where $x_{i, n}$ is a measure of $(\log )$ individual resources taking into account economies of scale and resource sharing as follows:

$$
x_{i, n}=x+\log \eta_{i, n}(x, \boldsymbol{p}, \boldsymbol{z})-\log s_{i, n}(x, \boldsymbol{p}, \boldsymbol{z}) .
$$

In this expression, $\eta_{i, n}>0$ represents the share of total expenditure accruing to individual $i$ belonging to a household of type $n$ and $s_{i, n}>0$ the economies of scale that are associated to this individual. This specification is explained in detail below.

Two important points must be made. First, the intuitive consequence of the specification above is that, after conditioning on observed demographic variables and the level of total resources, differences in expenditure patterns between a person living alone and a person living with others are attributed to joint consumption and resource sharing. Assuming the stability of individual 
preferences across household types is the key idea underlying the Rothbarth traditional approach to estimate child costs (see Gronau, 1988, 1991). In fact, this assumption is mitigated when the model accounts for additional flexibility in the form of scale economies, as discussed in Browning et al. (2008) and Bargain and Donni (2009). Indeed, terms accounting for how the "value" of total expenditure (or the shadow prices of all goods) changes due to publicness and externalities in consumption may well also capture changes in preferences over time and family status. These aspects are further discussed hereafter. Second, as mentioned above, the children living in the household are characterized by a unique indirect utility function, i.e., the children's preferences are aggregated into a unique index. This way of proceeding is made for the sake of simplicity but does not change the theoretical results. Also, it does not mean that we impose equal sharing among children: the total share $\eta_{c, 3}(x, \boldsymbol{p}, \boldsymbol{z})$ of children may possibly depend on characteristics $z$ that include the number of boys versus girls, or the age of children, in order to check for potential discrimination. ${ }^{7}$

Sharing Functions $\eta_{i, n}(x, \boldsymbol{p}, \boldsymbol{z})$. As often used in the collective model literature (e.g., Browning et al., 1994), we adopt a two-stage budget process that conveniently represents any efficient decision-making. This representation is in fact perfectly suited to our main purpose of retrieving children's resource shares and goes as follows. In a first stage, household resources $\exp (x)$ are supposed to be allocated between household members according to some sharing rule, i.e., the outcome of an unspecified decision process. Individual $i$ living in household of type $n>1$ receives a share $\eta_{i, n}(x, \boldsymbol{p}, \boldsymbol{z})$ of total expenditure $\exp (x)$. In a second stage, expenditures on all goods are chosen as if each individual solved her/his own utility maximization problem subject to an individual budget constraint, i.e., spent her/his own resources $\eta_{i, n} \cdot \exp (x)$. The sharing functions $\eta_{i, n}(x, \boldsymbol{p}, \boldsymbol{z})$ are differentiable, comprised between zero and one in such a way that the shares of all members sum up to unity. In the most general context, they depend on prices and total expenditure. For instance, we can imagine that the resources accruing to children vary with the price of child's clothing or toys. They also depend on a vector of household characteristics $\boldsymbol{z}$, which includes individual characteristics $\boldsymbol{z}_{i}$ and possibly some factors that capture the relative bargaining positions of the parents, which is potentially important to explain the level of expenditure devoted to children. To obtain our main identification results, we adopt the following assumption:

\footnotetext{
${ }^{7}$ Note that individual shares for each child can, in principle, be retrieved by extending the "Russian dolls" logic of the Rothbarth method. That is, by comparing the budget share of adult expenditure for couples with $N-1$ children to that of couples with $N$ children, ceteris paribus, we can retrieve information about how much resources have been allocated to the $N^{t h}$ child. This identification is however more fragile than what we present here and is kept for future research.
} 
A.1. The resource shares are differentiable functions that do not depend on total expenditure $x$, that is, $\eta_{i, n}(x, \boldsymbol{p}, \boldsymbol{z})=\eta_{i, n}(\boldsymbol{p}, \boldsymbol{z})$ for $i=m, w$ or $c$ and $n=2,3$.

While this assumption is potentially strong, it is made essentially for the sake of simplicity, as in Lewbel and Pendakur (2008), Bargain and Donni (2009) and Dunbar et al. (2010). In fact, it can be shown that identification results still hold if expenditures on several adult goods are observable (see Bargain and Donni, 2009). Also, A.1 can be mitigated in empirical applications by including measures of household wealth other than total expenditure in resource shares. In addition, notice that this assumption implies that the indifference/equivalence scales derived from the model are independent of the base, a property most often imposed in the traditional literature on equivalence scales.

Scaling Functions $s_{i, n}(x, \boldsymbol{p}, \boldsymbol{z})$. The publicness of goods, and hence economies of scale in the household, is represented by a particular technology of production. Following Lewbel and Pendakur (2008), we assume that the "value" of total expenditure is inflated by the presence of several persons in the household (e.g., a couple always riding the car together "consumes" actual car expenditures twice). The deflator $s_{i, n}<1$ is interpreted as a measure of the cost savings experienced by person $i$ as a result of scale economies in the household. For the purpose of identification, we introduce the following assumption:

A.2. The economies of scales are differentiable functions that do not depend on total expenditure $x$, that is, $s_{i, n}(x, \boldsymbol{p}, \boldsymbol{z})=s_{i, n}(\boldsymbol{p}, \boldsymbol{z})$ for $i=m$, w or $c$ and $n=2,3$.

This is the so-called 'independent of the base' (IB) assumption which refers to the fact that the economies of scale are assumed to be independent of the base expenditure (and hence utility) level at which they are evaluated. This assumption is similar to the IB restriction in the equivalence scale literature (Blackorby and Donaldson, 1993; Lewbel, 1991), but it concerns individual utility functions rather than aggregated household utility functions. The utility function of a person $i$ living in a household of type $n$ can thus be written as:

$$
u_{i, n}=v_{i}\left(\boldsymbol{p}, x+\log \eta_{i, n}(\boldsymbol{p}, \boldsymbol{z})-\log s_{i, n}(\boldsymbol{p}, \boldsymbol{z}), \boldsymbol{z}_{i}\right)
$$

The scaling function $s_{i, n}(\boldsymbol{p}, \boldsymbol{z})$ generally depends on all the individual characteristics of the persons living in the household, $\boldsymbol{z}$. Indeed, it cannot be excluded that the extent of joint consumption of one person in the household be related to the characteristics of her/his partner or her/his child. Moreover, since the degree of publicness in consumption depends on the type of good, the scaling function must be price-dependent. ${ }^{8}$ Finally, scaling functions must be

\footnotetext{
${ }^{8}$ The idea that some goods are consumed in common (and thereby largely affected by economies of scale) while other goods are not can be represented here, admittedly in a quite restrictive way, by the derivative of
} 
individual-specific, since economies of scale may differ between individuals within the same household, depending on how they value the good which is jointly consumed.

The flexibility offered by IB scales is particularly important. The arrival of a child in the household may indeed change consumption patterns and hence the degree of publicness in consumption in the household. Close to the notion of public goods, externalities of consumption, either positive or negative, may also characterize consumptions decisions in families. For instance, parents may decide to stop smoking and to change their leisure activities after the birth of a child. As discussed in Browning et al. (2008), scaling factors $s_{i, n}$ may embody positive/negative externalities within the household or changes in individual preferences across different household types. Admittedly, disentangling the different explanations is hard to achieve empirically. ${ }^{9}$ Importantly, even with the present IB simplification, this extended interpretation gives an additional argument in favor of making scaling factors individual-specific. It also shows that this additional flexibility contributes to mitigate the assumption of preference stability across household types, as previously discussed.

\subsection{Economies of Scale and Indifference Scales}

The present set-up allows us to define indifference scales in the sense of Lewbel (2003), Lewbel and Pendakur (2008) and Browning et al. (2008). Let us denote $\log I_{i, n}(\boldsymbol{p}, \boldsymbol{z})=\log s_{i, n}(\boldsymbol{p}, \boldsymbol{z})-$ $\log \eta_{i, n}(\boldsymbol{p}, \boldsymbol{z})$ so that equation (2) can be compactly written as:

$$
u_{i, n}=v_{i}\left(\boldsymbol{p}, x-\log I_{i, n}(\boldsymbol{p}, \boldsymbol{z}), \boldsymbol{z}_{i}\right)
$$

The term $I_{i, n}(\boldsymbol{p}, \boldsymbol{z})$ is the indifference scale of member $i$; it represents the income adjustment applied to this person in a multi-person household that would allow her/him to reach the same indifference curve if living alone. This concept differs from an ordinary equivalence scale, which attempts to compare the welfare of an individual to that of a household. In contrast, indifference scales can be seen as comparing the same individual in two different situations: living alone and living with a partner (with or without children). ${ }^{10}$ Note that with A.1 and A.2, indifference

$s_{i, n}(\boldsymbol{p}, \boldsymbol{z})$ with respect to prices. For instance, for goods that have a large public component (like housing), an increase in their price reduces the purchased quantity and thus has a positive effect on the scale $s_{i, n}(\boldsymbol{p}, \boldsymbol{z})(\mathrm{i} . \mathrm{e}$., a negative effect on economies of scale). In fact, IB scales can be seen as an approximation of Barten scales (see Lewbel and Pendakur, 2008).

${ }^{9}$ For instance, assume that married men care more about a cozy home than single men. Whether this is due to a change in taste, to the fact that they internalize the positive externality on their partner or to the effect of consuming "housing costs" jointly is a matter of speculation.

${ }^{10}$ Directly consistent with individualism, they avoid the difficulties related to the ill-defined concept of "household utility" and do not suffer from the fundamental identification problem associated with interpersonal comparisons (see Pollak and Wales, 1979). 
scales are independent of the base, a property which is often imposed in the equivalent scale literature (see Blackorby and Donaldson, 1993).

Finally, the deflator representing economies of scale $s_{i, n}(\boldsymbol{p}, \boldsymbol{z})$ cannot be interpreted directly. Indeed it generally ranges between $\eta_{i, n}(\boldsymbol{p}, \boldsymbol{z})$ (all the consumption is public) and 1 (all the goods are purely private). As it must be compared to the level of the individual share, we suggest a normalized indicator of the 'individual' economies of scale for each individual:

$$
\sigma_{i, n}(\boldsymbol{p}, \boldsymbol{z})=1+\frac{\eta_{i, n}(\boldsymbol{p}, \boldsymbol{z})\left(1-s_{i, n}(\boldsymbol{p}, \boldsymbol{z})\right)}{s_{i, n}(\boldsymbol{p}, \boldsymbol{z})\left(1-\eta_{i, n}(\boldsymbol{p}, \boldsymbol{z})\right)},
$$

for $n \geq 2$, which is equal to 1 in the purely private case and to 2 in the purely public case.

\subsection{The Budget Shares of Total Expenditure}

If the Roy's identity is applied to equation (2), and the derivative is developed, then individual $i$ 's budget share function for good $k$ is obtained as:

$$
\omega_{i, n}^{k}(\boldsymbol{p}, x, \boldsymbol{z})=\lambda_{i, n}^{k}(\boldsymbol{p}, \boldsymbol{z})+w_{i}^{k}\left(\boldsymbol{p}, x-\log I_{i, n}(\boldsymbol{p}, \boldsymbol{z}), \boldsymbol{z}_{i}\right)
$$

where $\omega_{i, n}^{k}(\boldsymbol{p}, x, \boldsymbol{z})$ is the share of member $i$ 's resources $\exp (x) \times \eta_{i, n}(\boldsymbol{p}, \boldsymbol{z})$ that are spent on good $k$ and $\lambda_{i, n}^{k}(\boldsymbol{p}, \boldsymbol{z})=\partial \log s_{i, n}(\boldsymbol{p}, \boldsymbol{z}) / \partial p^{k}$ is the elasticity of $s_{i, n}(\boldsymbol{p}, \boldsymbol{z})$ with respect to the $k$-th price. The consequence of the IB assumption in the present context is that the budget share equations of person $i$ living in a household of type $n$ differ from when alone in that they are translated over by $\lambda_{i, n}^{k}(\boldsymbol{p}, \boldsymbol{z})$ while $\log$ household expenditure $x$ is translated over by $\log I_{i, n}(\boldsymbol{p}, \boldsymbol{z})$. This property is referred to as "shape invariance" by Pendakur (1999). ${ }^{11}$ To unify our notation, we also introduce the following definitions.

N.1. For single households $(n=1)$, we have: $\eta_{i, 1}(p, z)=1, \lambda_{i, n}^{k}(p, z)=0, s_{i, n}(p, z)=1$ for $i=w$ or $m$ and $k=1, \ldots, K$.

This condition is also a normalization. It implicitly means that single individuals are used as the demographic structure of reference. Now, let us suppose that households are observed in a unique price regime, as provided in cross-sectional data, so that the vector of prices $\boldsymbol{p}$ is constant and can be taken out of equation (4). Formally, the implications of the IB assumption in a framework with no price variation are described in the following lemma.

\footnotetext{
${ }^{11}$ The translation function $\lambda_{i, n}^{k}(\boldsymbol{p}, \boldsymbol{z})$ is specific to good $k$ and related to the differences that may exist between goods with respect to the possibility of joint consumption. Intuitively, economies of scale may have a wealth effect and a substitution effect. The former is represented by $\log s_{i, n}(\boldsymbol{p}, \boldsymbol{z})$ and the latter by $\lambda_{i, n}^{k}(\boldsymbol{p}, \boldsymbol{z})$. The substitution effect is positive (negative) if good $k$ is essentially public (private).
} 
Lemma 1 (Lewbel and Pendakur, 2008). Assume A.1-A.2 and N.1. If prices are constant, the budget share of good $k$ of person $i$ living in household of type $n$ is written:

$$
\begin{aligned}
& \omega_{i, n}^{k}(x, \boldsymbol{z})=\lambda_{i, n}^{k}(\boldsymbol{z})+w_{i}^{k}\left(x-\log I_{i, n}(\boldsymbol{z}), \boldsymbol{z}_{i}\right), \\
& \quad \text { for } \quad i=w, m, c, \quad n=1,2,3, \quad \text { and } \quad k=1, \ldots, K .
\end{aligned}
$$

where $\log I_{i, n}(z)=\log s_{i, n}(z)-\log \eta_{i, n}(z)$ is the $\log$ deflator of total expenditure which combines scaling $s_{i, n}$ and sharing $\eta_{i, n}$.

The left-hand side of expression (5) represents the 'reduced-form' budget share on good $k$ of person $i$ in household of type $n$ as a function of (log) household resources $x$ and household characteristics $\boldsymbol{z}$. The right-hand side puts some structure on this budget share as a result of the IB restriction: the individual budget share function $w_{i}^{k}\left(\cdot, \boldsymbol{z}_{i}\right)$ of person $i$ depends on her/his individual resources adjusted by the scaling $s_{i, n}(\boldsymbol{z})$ and on individual characteristics $\boldsymbol{z}_{i}$ (but not on the characteristics of the other individuals in the household); this budget share is then translated by the elasticity $\lambda_{i, n}^{k}(\boldsymbol{z})$.

Household expenditures on each good $k$ can be written as the sum of individual expenditures on that good. Dividing this identity by the total outlay $\exp (x)$, we obtain directly the household budget share function for any good $k$ as:

$$
W_{n}^{k}(x, \boldsymbol{z})=\sum_{i \in \varphi_{n}} \eta_{i, n}(\boldsymbol{z}) \cdot \omega_{i, n}^{k}(x, \boldsymbol{z})
$$

for households of any type $n$, where $\varphi_{n}$ is the set of the index of persons living in a household of type $n$. This is simply the sum of individual budget share equations over all household members, weighted by their individual resource shares.

\subsection{Identification Results}

Our goal here is to identify the important structural elements of the model, namely the sharing functions and the scaling functions, from demand data. To account for unobserved factors, we add error terms to the household budget shares previously defined:

$$
\widetilde{W}_{n}^{k}(x, \boldsymbol{z})=W_{n}^{k}(x, \boldsymbol{z})+\varepsilon_{n}^{k}, \text { for } n=1,2,3 \text { and } k=1, \ldots, K,
$$

where $\widetilde{W}_{n}^{k}(x, \boldsymbol{z})$ is the stochastic extension of $W_{n}^{k}(x, \boldsymbol{z})$. Error terms $\varepsilon_{n}^{k}$ are traditionally interpreted as optimization/measurement errors or, alternatively, as resulting from unobservable heterogeneity in the individual budget share equations (hence assuming random utilities), in the scales or in the resource shares. The equations (??) can be identified from well-known results in non-parametric econometrics provided the sample is sufficiently large and error terms satisfy 
normalization restrictions (see Matzkin, 2007, for instance). Identification thus concentrates on how to retrieve the structural components $s_{i, n}(\boldsymbol{z})$, and $\eta_{i, n}(\boldsymbol{z})$, for $i=w, m$ or $c$ and $n=1,2,3$, from the knowledge of the deterministic components $W_{n}^{k}(x, \boldsymbol{z})$.

The identification result that follows relies on a certain number of normalization conditions. First of all, the condition N.1 previously discussed is obviously necessary. Moreover, the terms that represent economies of scale in the budget share equations of children are actually meaningless in a world where young children always live within the same family structure. Hence, without loss of generality, the following condition is also used.

N.2. For households with children $(n=3)$, we have: $\lambda_{c, n}^{k}(\boldsymbol{z})=0, s_{c, n}(\boldsymbol{z})=0$ for $k=1, \ldots, K$. The main result is then summarized in the following proposition.

Proposition 1. Assume A.1-A.2 and N.1-N.2. The econometrician observes at least one adultspecific good for each adult living in the household. More precisely, one good $k_{m}$ is consumed by men but not by women or children and one other good $k_{w}$ is consumed by women but not by men or children. The budget share equations for these goods satisfy the following conditions:

1. $\nabla_{x} w_{i}^{k_{i}}\left(x_{i, n}, \boldsymbol{z}_{i}\right) \neq 0$ and $\nabla_{x x} w_{i}^{k_{i}}\left(x_{i, n}, \boldsymbol{z}_{i}\right) \neq 0$ almost everywhere for $i=m$ or $w$,

2. the function $\Delta_{i}^{k_{i}}\left(x_{i, n}, \boldsymbol{z}_{i}\right) \equiv \nabla_{x} w_{i}^{k_{i}}\left(x_{i, n}, \boldsymbol{z}_{i}\right) \cdot\left[\nabla_{x x} w_{i}^{k_{i}}\left(x_{i, n}, \boldsymbol{z}_{i}\right)\right]^{-1}$ is not periodic in its first argument for $i=m$ or $w$.

Then, if prices are constant, the sharing functions $\eta_{i, n}(\boldsymbol{z})$ and the scaling functions $s_{i, n}(\boldsymbol{z})$, for $i=m, w$ or $c$ and $n=1,2,3$, can be identified from the estimation of the budget share equations $W_{n}^{k_{i}}(x, \boldsymbol{z})$ on the adult-specific goods.

In other words, identification will exploit the existence of adult goods (such as male and female clothing) along the lines of the Rothbarth method. In addition, the budget share equations must be non linear in total expenditure. ${ }^{12}$ Note that generic identification can also be obtained theoretically when there is only one adult-specific good (for instance, if adult male and female clothing could not be distinguished in expenditure data), yet it is empirically less robust. Genderspecific clothing expenditure are often available anyway. The proof of Proposition 1 follows in three steps.

\footnotetext{
${ }^{12}$ Recall that a periodic function is a function $f(x)$ such that $f(x)=f(x+t)$ for some scalar $t$. This is a very particular property that most functions do not satisfy. In particular, a monotonic function is not periodic.
} 
Step 1: $n=1$. The "basic" budget share equations are simply retrieved by using information on singles. That is, for $n=1$ and using normalization N.1, we simply have:

$$
W_{1}^{k}(x, \boldsymbol{z})=w_{i}^{k}\left(x, \boldsymbol{z}_{i}\right)
$$

for any $k$, with $i=m$ or $w$, so that identification of the functions $w_{i}^{k}(\cdot)$ can be obtained from a sample of single male and female individuals.

Step 2: $n=2$. The household budget share equations for adult good $k_{i}$ can be written as:

$$
W_{2}^{k_{i}}(x, \boldsymbol{z})=\eta_{i, 2}(\boldsymbol{z}) \cdot\left[\lambda_{i, 2}^{k_{i}}(\boldsymbol{z})+w_{i}^{k_{i}}\left(x-\log I_{i, 2}(\boldsymbol{z}), \boldsymbol{z}_{i}\right)\right],
$$

for $i=m$ or $w$ (this good is specific to only one person in the household). To eliminate the function $\lambda_{i, 2}^{k_{i}}(\boldsymbol{z})$ from equation (7), we compute the first-order derivative of this expression with respect to $x$ and obtain:

$$
\nabla_{x} W_{2}^{k_{i}}(x, \boldsymbol{z})=\eta_{i, 2}(\boldsymbol{z}) \nabla_{x} w_{i}^{k_{i}}\left(x-\log I_{i, 2}(\boldsymbol{z}), \boldsymbol{z}_{i}\right)
$$

where the left-hand side of this expression is identified. Differentiating again this expression with respect to $x$ we obtain the second-order derivative:

$$
\nabla_{x x} W_{2}^{k_{i}}(x, \boldsymbol{z})=\eta_{i, 2}(\boldsymbol{z}) \nabla_{x x} w_{i}^{k}\left(x-\log I_{i, 2}(\boldsymbol{z}), \boldsymbol{z}_{i}\right) .
$$

Taking the ratio of (8) and (9), we have:

$$
\frac{\nabla_{x} W_{2}^{k_{i}}(x, \boldsymbol{z})}{\nabla_{x x} W_{2}^{k_{i}}(x, \boldsymbol{z})}=\frac{\nabla_{x} w_{i}^{k_{i}}\left(x-\log I_{i, 2}(\boldsymbol{z}), \boldsymbol{z}_{i}\right)}{\nabla_{x x} w_{i}^{k_{i}}\left(x-\log I_{i, 2}(\boldsymbol{z}), \boldsymbol{z}_{i}\right)} \equiv \Delta_{i}^{k_{i}}\left(x+\log I_{i, 2}(\boldsymbol{z}), \boldsymbol{z}\right)
$$

where the left-hand side of the first equality and the function $\Delta_{i}^{k_{i}}(\cdot, \boldsymbol{z})$ are known from step 1. This condition uniquely identifies the indifference scales $I_{i, 2}(\boldsymbol{z})$ for $i=m$ or $w$, provided the function $\Delta_{i}^{k_{i}}(\cdot)$ is not periodic in its first argument. Indeed, let us suppose $\boldsymbol{z}=\overline{\boldsymbol{z}}$ is constant and can be eliminated from the arguments of the functions. Then let us consider another solution $I_{i, 2}^{\prime}$ for the equation above so that:

$$
\Delta_{i}^{k_{i}}\left(x+\log I_{i, 2}\right)=\Delta_{i}^{k_{i}}\left(x+\log I_{i, 2}^{\prime}\right)
$$

Since $\Delta_{i}^{k_{i}}(\cdot)$ is not periodic, this equality is not possible for any value of $x$. Therefore, the solution $I_{i, 2}$ must be unique. Then, for $i=m$ or $w$, identification of sharing functions $\eta_{i, 2}(\boldsymbol{z})$ follows from (8) and identification of translation functions $\lambda_{i, 2}^{k_{i}}(\boldsymbol{z})$ from (7). Finally, the scaling functions $s_{i, 2}(\boldsymbol{z})$ can be computed for $i=m$ or $w$ from the definition of $I_{i, 2}(\boldsymbol{z})$. 
Step 3: $n=3$. The household budget share equations for adult goods $k_{i}$ have exactly the same structure as above:

$$
W_{3}^{k_{i}}(x, \boldsymbol{z})=\eta_{i, 3}(\boldsymbol{z}) \cdot\left[\lambda_{i, 3}^{k_{i}}(\boldsymbol{z})+w_{i}^{k_{i}}\left(x-\log I_{i, 3}(\boldsymbol{z}), \boldsymbol{z}_{i}\right)\right]
$$

for $i=m$ or $w$. Hence, identification of $\eta_{i, 3}(\boldsymbol{z}), s_{i, 3}(\boldsymbol{z})$ and $I_{i, 3}(\boldsymbol{z})$ for $i=m$ or $w$ is straightforward. The share of total expenditure devoted to children is then obtained as:

$$
\eta_{c, 3}(\boldsymbol{z})=1-\eta_{m, 3}(\boldsymbol{z})-\eta_{w, 3}(\boldsymbol{z})
$$

while the scaling function $s_{c, 3}(\boldsymbol{z})$ is given by normalization N.2.

\section{Empirical Implementation}

\subsection{Functional Forms}

We turn to the empirical specification of the complete model, suggesting a parameterization that balances flexibility and empirical tractability. The first component, which appears in the specification of the different demographic groups, is the "basic" budget share equation. We introduce an index $h$ for the observation and adopt the following quadratic specification:

$$
w_{i, h}^{k}=a_{i}^{k} \boldsymbol{z}_{i, h}+b_{i}^{k} \cdot\left(x_{i, n, h}-\mu_{i} \boldsymbol{z}_{i, h}\right)+c_{i}^{k} \cdot\left(x_{i, n, h}-\mu_{i} \boldsymbol{z}_{i, h}\right)^{2}, \text { for } i=w, m, c \text { and } k=1, \ldots, K
$$

where $x_{i, n, h}$ is defined as previously for observation $h, b_{i}^{k}$, and $c_{i}^{k}$ are parameters and $a_{i}^{k} \boldsymbol{z}_{i, h}$ and $\mu_{i} \boldsymbol{z}_{i, h}$ are linear functions of the socio-demographic variables $\boldsymbol{z}_{i, h}$ defined below. For adults, the parameters and functions are gender-specific (with $i=m$ for men, $i=w$ for women) but do not depend on the demographic type $n$ nor on the number of children, since the "basic" adult budget share equations are the same for single women (resp. men) and for women (resp. men) living in a couple. The demographic variables enter the specification both as a translation of budget share equations and as a translation of log scaled expenditure. For adults, the latter characteristics, those entering $\mu_{i} \boldsymbol{z}_{i, h}$, include age and a dummy for "no education". The former, those entering $a_{i}^{k} \boldsymbol{z}_{i, h}$, include the same variables plus a constant, dummies for house ownership and urban resident. For children, the characteristics entering $a_{i}^{k} \boldsymbol{z}_{i, h}$ include a constant, the average age of the children and the proportion of male children in the household.

Next, we specify the household budget share equations. For single male and female adults, they coincide with the "basic" budget share equations specified above plus an additive error term, that is,

$$
\widetilde{W}_{1, h}^{k}=w_{i}^{k}\left(x_{h}, \boldsymbol{z}_{i, h}\right)+\varepsilon_{1, h}^{k} .
$$


For multi-person households $n \geq 2$, and for non-adult-specific goods, the household budget share equations,

$$
\widetilde{W}_{n, h}^{k}=\sum_{i \in \varphi_{n, h}} \eta_{i, n}\left(\boldsymbol{z}_{h}\right)\left[\lambda_{i, n}^{k}\left(\boldsymbol{z}_{h}\right)+w_{i}^{k}\left(x_{h}-\log I_{i, n}\left(\boldsymbol{z}_{h}\right), \boldsymbol{z}_{i, h}\right)\right]+\varepsilon_{n, h}^{k},
$$

comprise the individual functions $w_{i}^{k}\left(\cdot, \boldsymbol{z}_{i, h}\right)$ as already specified and three other components that are defined as follows. First, the resource sharing functions are specified using the logistic form:

$$
\eta_{i, n}\left(\boldsymbol{z}_{h}\right)=\frac{\exp \left(\alpha_{i, n}+\beta_{i} \boldsymbol{z}_{h}\right)}{\sum_{j \in \varphi_{n, h}} \exp \left(\alpha_{j, n}+\beta_{j} \boldsymbol{z}_{h}\right)}, \quad \quad \text { for } i=m, w, c
$$

where $\alpha_{i, n}$ are parameters and $\beta_{i} \boldsymbol{z}_{h}$ are linear functions of the household characteristics. To limit the number of parameters, variables in $\beta_{i} z_{h}$ include spouses' age, the "no education" dummy of each spouse and a urban dummy. Normalization is obviously required and we simply set the coefficients of the exponential corresponding to the wife to zero. For the share of children, we include the proportion of male children and the average age of the children in the household. As indicated above, and because we want the share of children to vary with the presence of children in a flexible way, we introduce dummies for households with two and three children. Second, the log scaling functions that translate expenditure within the basic budget shares can be written as:

$$
\log s_{i, n}\left(\boldsymbol{z}_{h}\right)=A_{i, n}+B_{i} \boldsymbol{z}_{h}, \quad \text { for } i=m, w
$$

where $A_{i, n}$ are parameters and $B_{i} \boldsymbol{z}_{h}$ linear functions of the characteristics. The scaling functions can in principle vary with all the variables entering preferences. In our specification, however, it is restricted to depend only on variables specific to individual $i$ for adults (education and age). To limit the number of parameters, only the constant is indexed by the type of family $n$. Third, the function that translates the basic budget shares $\lambda_{i, n}^{k}(\boldsymbol{z})$ is a price elasticity. Measuring price effects is generally challenging - and it is all the more difficult to capture their interaction with demographics in any plausible way. Therefore we restrict these terms to be constant (and normalized to zero for children, as explained above):

$$
\lambda_{i, n}^{k}(\boldsymbol{z})=D_{i, n}^{k}, \quad \text { for } i=m \text { or } w, n=2,3, \text { and } k=1, \ldots, K
$$

\subsection{Estimation Method}

The complete model is estimated by the iterated SURE method. To account for the likely correlation between the error terms $\varepsilon_{n, h}^{k}$ in each budget share function and the log total expenditure, each budget share equation is augmented with the 'Wu-Hausman' residuals (Banks et al., 
1997; Blundell and Robin, 1999). To allow for sufficient flexibility of the covariance matrices, we shall now consider six demographic groups (instead of three in what precedes) indexed by $n_{e}=1, \ldots, 6$ (for single males, single females, childless couples, couples with one to three children respectively). Hence, for each group separately, the residual is obtained from reduced-form estimations of $x$ on all exogenous variables used in the model plus some excluded instruments. For the latter, we choose the inverse of household disposable income and a fourth order polynomials in its logarithm. Since budget shares sum up to one, equation for good $K$ is unnecessary. The household budget share equations for the $K-1$ goods and for the six demographic groups are estimated simultaneously. The error terms are supposed to be uncorrelated across households but correlated across goods within households. They are supposed to be homoskedastic for each family type $n$. Observations in the data are indexed by $h$ and the number of observation in each demographic group is denoted by $H_{n_{e}}$, with $n_{e}=1, \ldots, 6$. Let $\mathbf{W}_{n_{e}, h}$ be the $(K-1)$ vector of observed budget shares for the first $K-1$ goods consumed by household $h$ of type $n_{e}$ and let $\hat{\mathbf{W}}_{n_{e}, h}(\boldsymbol{\theta})$ be the corresponding $(K-1)$ vector of predicted budget shares for some parameter vector $\boldsymbol{\theta}$. The vector of residuals is thus given by $\boldsymbol{\varepsilon}_{n_{e}, h}(\boldsymbol{\theta})=\mathbf{W}_{n_{e}, h}-\hat{\mathbf{W}}_{n_{e}, h}(\boldsymbol{\theta})$. If $\hat{\boldsymbol{\varepsilon}}_{n_{e}, h}=\boldsymbol{\varepsilon}_{n_{e}, h}\left(\hat{\boldsymbol{\theta}}_{0}\right)$, where $\hat{\boldsymbol{\theta}}_{0}$ is any initial consistent estimation of the vector of parameters, the estimated covariance matrix can be defined by

$$
\hat{\mathbf{V}}_{n_{e}}=H_{n_{e}}^{-1} \times\left(\hat{\varepsilon}_{n_{e}, h}\right)\left(\hat{\varepsilon}_{n_{e}, h}\right)^{\prime}
$$

The SURE criterion is then:

$$
\min _{\boldsymbol{\theta}} \sum_{n_{e}=1}^{6} \sum_{h=1}^{H_{j}}\left(\varepsilon_{n_{e}, h}(\boldsymbol{\theta})\right)^{\prime}\left(\hat{\mathbf{V}}_{n_{e}}\right)^{-1}\left(\boldsymbol{\varepsilon}_{n_{e}, h}(\boldsymbol{\theta})\right),
$$

which gives a new value $\hat{\boldsymbol{\theta}}_{1}$ for the estimates. The estimation procedure is then iterated with the new estimates until the covariance matrix converges.

\subsection{Data and Sample Selection}

The availability and quality of data from Côte d'Ivoire has attracted a large number of empirical studies (Deaton, 1989, 1997; Duflo and Udry, 2004; Hoddinott and Haddad, 1991, 1995, among others). In our empirical analysis, we make use of the most recent available survey for this country, namely the Côte d'Ivoire 2002 Living Standard Survey (CILSS, Enquête Niveau de Vie des Ménages) conducted by the Institut National de la Statistique between January and December 2002. This is a cross sectional national survey which collects information on household expenditure, incomes and socio-demographics with an initial sample of 10, 800 households. While price inflation has been high during the second half of the 2000s, it was relatively small in 2002 $(2.5 \%)$ so that the sample can be treated as cross-sectional data. 
We restrict the sample to monogamous, nuclear households (i.e., either a single adult or a married couple with or without children). This selection drops $50 \%$ of the initial sample. We further restrict our sample to households where adults are aged between $18-64$ years, which excludes another $4 \%$ of the sample. We drop households with children whose age is above 16 years, to ensure that we can distinguish children's clothing from adults clothing, as these are the central goods used in the identification of our model. We also drop households with more than three children since they are primarily composed of older children. By this selection we drop 10\% of the initial sample. We finally exclude single women living with children (5\%), households where men are not economically active $(2 \%)$ and households with zero food expenditure together with obvious outlying observations $(2 \%)$. This selection leaves us with 2,920 households (27\% of the initial sample), described in Table 1.

Formally, a pair of adult-specific goods (i.e., male and female clothing) and a residual good are just what we need to identify children's resource shares, as explained in the previous section. However, we consider other non-durable goods to improve the efficiency of the estimations: food, transport and communication, personal goods and services, leisure goods and services, household operations and housing costs (composed of maintenance costs, rental costs and imputed housing costs for house owners). ${ }^{13}$ We also include a child-specific good (i.e., child clothing). Thus, our estimation use observations for $K=9$ non-durable commodities, housing being the omitted good in the Engel curve system. This system comprises 6 non-exclusive good, with three individual budget shares (two for the adults and one for children), and 3 assignable goods (adult male, adult female and child clothing); hence a total of 21 individual Engel curves.

Budget information is collected via a questionnaire where respondents are asked to report expenditures on various goods. Food expenditures are recorded with a recall period of last seven days and last month while clothing expenditure which is central to our analysis has a recall period of last 12 months. This helps to avoid too many zeros due to infrequency of purchase for the key goods in our analysis. The lower part of Table 1 reports reassuringly high proportions of strictly positive values for adult and child clothing.

\footnotetext{
${ }^{13}$ Traditionally, expenditures on housing are not modeled. Nonetheless, we believe that expenditure on housing cannot be ignored in our analysis as they may be an important contributor to household economies of scale and are also important when addressing poverty issues (as we do). Note, however, that the size of the household may be correlated with housing decisions.
} 
Table 1: Summary statistics

\begin{tabular}{|c|c|c|c|c|c|c|}
\hline & $\begin{array}{c}\begin{array}{c}\text { single } \\
\text { men }\end{array} \\
\end{array}$ & $\begin{array}{c}\text { single } \\
\text { women }\end{array}$ & $\begin{array}{c}\text { childless } \\
\text { couple }\end{array}$ & $\begin{array}{c}\text { couple }+1 \\
\text { children } \\
\end{array}$ & $\begin{array}{c}\text { couple }+2 \\
\text { children }\end{array}$ & $\begin{array}{c}\text { couple }+3 \\
\text { children }\end{array}$ \\
\hline Age (male)* & $\begin{array}{c}33.4 \\
(10.0)\end{array}$ & - & $\begin{array}{l}35.1 \\
(9.8)\end{array}$ & $\begin{array}{l}33.8 \\
(8.3)\end{array}$ & $\begin{array}{l}36.7 \\
(8.9)\end{array}$ & $\begin{array}{l}38.6 \\
(8.2)\end{array}$ \\
\hline Age (female) & - & $\begin{array}{c}38.2 \\
(13.1)\end{array}$ & $\begin{array}{l}27.2 \\
(9.0)\end{array}$ & $\begin{array}{l}25.5 \\
(6.9)\end{array}$ & $\begin{array}{l}28.0 \\
(7.3)\end{array}$ & $\begin{array}{l}30.1 \\
(7.1)\end{array}$ \\
\hline No schooling (male) & $\begin{array}{c}0.49 \\
(0.50)\end{array}$ & - & $\begin{array}{c}0.47 \\
(0.50)\end{array}$ & $\begin{array}{c}0.52 \\
(0.50)\end{array}$ & $\begin{array}{c}0.53 \\
(0.50)\end{array}$ & $\begin{array}{c}0.58 \\
(0.49)\end{array}$ \\
\hline No schooling (female) & $(0.00)$ & $\begin{array}{c}0.54 \\
(0.50)\end{array}$ & $\begin{array}{c}0.64 \\
(0.48)\end{array}$ & $\begin{array}{c}0.70 \\
(0.46)\end{array}$ & $\begin{array}{c}0.73 \\
(0.44)\end{array}$ & $\begin{array}{c}0.77 \\
(0.42)\end{array}$ \\
\hline House owner & $\begin{array}{c}0.23 \\
(0.42)\end{array}$ & $\begin{array}{c}0.28 \\
(0.45)\end{array}$ & $\begin{array}{c}0.38 \\
(0.49)\end{array}$ & $\begin{array}{c}0.37 \\
(0.48)\end{array}$ & $\begin{array}{c}0.48 \\
(0.50)\end{array}$ & $\begin{array}{c}0.54 \\
(0.50)\end{array}$ \\
\hline Rural & $\begin{array}{c}0.48 \\
(0.50)\end{array}$ & $\begin{array}{c}0.51 \\
(0.50)\end{array}$ & $\begin{array}{c}0.55 \\
(0.50)\end{array}$ & $\begin{array}{c}0.54 \\
(0.50)\end{array}$ & $\begin{array}{c}0.62 \\
(0.49)\end{array}$ & $\begin{array}{c}0.65 \\
(0.48)\end{array}$ \\
\hline Household expenditure (\$/week)** & $\begin{array}{c}14.3 \\
(10.2)\end{array}$ & $\begin{array}{c}15.3 \\
(11.3)\end{array}$ & $\begin{array}{c}20.3 \\
(12.9)\end{array}$ & $\begin{array}{c}20.9 \\
(14.1)\end{array}$ & $\begin{array}{c}21.0 \\
(15.2)\end{array}$ & $\begin{array}{c}21.5 \\
(17.1)\end{array}$ \\
\hline Household expenditure (\$/week) ${ }^{* * *}$ & $\begin{array}{c}37.5 \\
(28.9)\end{array}$ & $\begin{array}{l}41.2 \\
(25 .)\end{array}$ & $\begin{array}{c}54.6 \\
(34.3)\end{array}$ & $\begin{array}{c}56.6 \\
(35.3)\end{array}$ & $\begin{array}{c}60.0 \\
(41.5)\end{array}$ & $\begin{array}{c}66.2 \\
(53.1)\end{array}$ \\
\hline Average age of children & - & - & - & $\begin{array}{c}3.4 \\
(3.5)\end{array}$ & $\begin{array}{c}5.0 \\
(3.2)\end{array}$ & $\begin{array}{c}5.9 \\
(2.7)\end{array}$ \\
\hline Prop. of male children & - & - & - & $\begin{array}{c}0.49 \\
(0.50)\end{array}$ & $\begin{array}{c}0.51 \\
(0.36)\end{array}$ & $\begin{array}{c}0.52 \\
(0.30)\end{array}$ \\
\hline \multicolumn{7}{|l|}{ Budget shares: } \\
\hline Food & $\begin{array}{l}0.50 \\
(0.20)\end{array}$ & $\begin{array}{c}0.51 \\
(0.18)\end{array}$ & $\begin{array}{c}0.49 \\
(0.18)\end{array}$ & $\begin{array}{c}0.52 \\
(0.17)\end{array}$ & $\begin{array}{c}0.53 \\
(0.17)\end{array}$ & $\begin{array}{c}0.54 \\
(0.16)\end{array}$ \\
\hline Personal goods and services & $\begin{array}{c}0.10 \\
(0.09)\end{array}$ & $\begin{array}{c}0.10 \\
(0.09)\end{array}$ & $\begin{array}{c}0.09 \\
(0.07)\end{array}$ & $\begin{array}{c}0.09 \\
(0.06)\end{array}$ & $\begin{array}{c}0.09 \\
(0.06)\end{array}$ & $\begin{array}{c}0.09 \\
(0.06)\end{array}$ \\
\hline Leisure goods and services & $\begin{array}{c}0.04 \\
(0.08)\end{array}$ & $\begin{array}{c}0.01 \\
(0.03)\end{array}$ & $\begin{array}{c}0.03 \\
(0.06)\end{array}$ & $\begin{array}{c}0.02 \\
(0.05)\end{array}$ & $\begin{array}{c}0.02 \\
(0.05)\end{array}$ & $\begin{array}{c}0.02 \\
(0.05)\end{array}$ \\
\hline Household operations & $\begin{array}{c}0.07 \\
(0.07)\end{array}$ & $\begin{array}{c}0.10 \\
(0.09)\end{array}$ & $\begin{array}{c}0.08 \\
(0.08)\end{array}$ & $\begin{array}{c}0.08 \\
(0.07)\end{array}$ & $\begin{array}{c}0.08 \\
(0.07)\end{array}$ & $\begin{array}{c}0.08 \\
(0.07)\end{array}$ \\
\hline Housing & $\begin{array}{c}0.17 \\
(0.13)\end{array}$ & $\begin{array}{c}0.19 \\
(0.15)\end{array}$ & $\begin{array}{c}0.16 \\
(0.13)\end{array}$ & $\begin{array}{c}0.14 \\
(0.11)\end{array}$ & $\begin{array}{c}0.14 \\
(0.10)\end{array}$ & $\begin{array}{c}0.14 \\
(0.10)\end{array}$ \\
\hline Transport and communication & $\begin{array}{c}0.09 \\
(0.12)\end{array}$ & $\begin{array}{c}0.06 \\
(0.08)\end{array}$ & $\begin{array}{c}0.09 \\
(0.11)\end{array}$ & $\begin{array}{c}0.07 \\
(0.09)\end{array}$ & $\begin{array}{c}0.07 \\
(0.10)\end{array}$ & $\begin{array}{c}0.06 \\
(0.08)\end{array}$ \\
\hline \multicolumn{7}{|l|}{ Budget shares (exclusive goods) } \\
\hline Women's clothing & - & $\begin{array}{c}0.042 \\
(0.041)\end{array}$ & $\begin{array}{c}0.043 \\
(0.037)\end{array}$ & $\begin{array}{c}0.037 \\
(0.029)\end{array}$ & $\begin{array}{c}0.036 \\
(0.030)\end{array}$ & $\begin{array}{c}0.036 \\
(0.029)\end{array}$ \\
\hline Men's clothing & $\begin{array}{c}0.040 \\
(0.043)\end{array}$ & - & $\begin{array}{c}0.023 \\
(0.019)\end{array}$ & $\begin{array}{c}0.022 \\
(0.023)\end{array}$ & $\begin{array}{c}0.020 \\
(0.022)\end{array}$ & $\begin{array}{c}0.019 \\
(0.020)\end{array}$ \\
\hline Children's clothing & - & - & - & $\begin{array}{c}0.020 \\
(0.020)\end{array}$ & $\begin{array}{c}0.026 \\
(0.026)\end{array}$ & $\begin{array}{c}0.032 \\
(0.024)\end{array}$ \\
\hline Total clothing & 0.040 & 0.042 & 0.066 & 0.079 & 0.082 & 0.086 \\
\hline \multicolumn{7}{|l|}{ Proportion of positive values: } \\
\hline Women's clothing & - & 0.73 & 0.88 & 0.90 & 0.87 & 0.89 \\
\hline Men's clothing & 0.83 & - & 0.82 & 0.79 & 0.76 & 0.80 \\
\hline Children's clothing & - & - & - & 0.92 & 0.94 & 0.95 \\
\hline Sample size & 969 & 223 & 335 & 526 & 514 & 353 \\
\hline
\end{tabular}




\section{$5 \quad$ Empirical Results}

\subsection{A First Look at the Data}

Table 1 provides descriptive statistics of our sample by household type and the number of children. We observe that around half of adult men and up to three-quarter of adult women have no education, which justifies the choice of a simple dummy ("no education") in the aforementioned specification of the empirical model. Other characteristics are in line with common wisdom about a developing country like Côte d'Ivoire. In particular, budget shares show that food is the main item, representing around half of household expenditure, which is a similar proportion as in previous surveys using CILSS data (Haddad et al., 1994, Hoddinott and Haddad, 1994, Duflo and Udry, 2004, Udry and Woo, 2006). Importantly for our purpose is the shift in consumption patterns of adult-specific goods as household composition changes. We find that the presence of children in the household reduces the budget shares devoted to parents' clothing. While couples without children allocate $4.3 \%$ and $2.3 \%$ of their budget to women and men's clothing respectively, this drops to $3.7 \%$ and $2.2 \%$ (3.6\% and 2.0\%) respectively in couples with one child (two children). Expenditures in absolute terms also decrease. ${ }^{14}$ The pattern uncovered here is in line with the widely accepted notion that children impose economic costs on their parents. According to the Rothbarth intuition, the arrival of a child is similar to an income effect which decreases the welfare parents get out of consumption as they re-allocate their limited resources to accommodate children's needs. At the same time, Table 1 shows that the budget share of the typically private goods (i.e., food, total clothing, and to a lesser extent, leisure expenditure) increases with the size of the household while the budget share of typically public goods (i.e., housing, and to a less extent, transport) decreases. ${ }^{15}$ A simple interpretation is that economies of scale are substantial, and not the same for all goods. ${ }^{16}$ That is, economies of scale generate

\footnotetext{
${ }^{14}$ For instance, while the average yearly expenditure on male (female) clothing, expressed in PPP dollars, is 23.1 (41.3) in childless couples, it drops to 22.1 and 19.3 (35.1 and 32.8) in couples with one and two children respectively.

${ }^{15}$ This is also true when controlling for total outlay.

${ }^{16}$ Economies of scale in food consumption may exist too. This is particularly the case for households with two or more adults relative to single adults living alone (Deaton and Paxson, 1998, Vernon, 2005, Browning et al., 2006). This is confirmed here with a slight decrease of food share in childless couples compared to singles. When children enter the picture, the "privateness" of food and the fact that children are more food intensive than parents prevail and lead to the observed increase in food share. The fact that children's food consumption is disproportionately higher makes that the cost of children is usually overestimated when calculated on the basis of variations in food expenditure across household types, i.e., the Engel approach (see Deaton, 1997). The Rothbarth approach based on adult goods avoids this critique.
} 
an effect that incites consumption of private goods (substituting away from public goods). ${ }^{17}$ Among the preliminary inspections of the data, we have also checked for endogeneity of total expenditure and for the non-linearity of budget share equations in log expenditure (especially for adult goods, as explained above). To do so, we have performed reduced-form estimations on the subsample of each household type $n_{e}$. Estimates are available from the authors and we simply summarize the main results here. The budget shares for male and female clothing are regressed on age, the dummies for education, house ownership and urban residency, as well as the log total expenditure, its square and the Wu-Hausman residual. The coefficients of log expenditure and its square show a quadratic pattern in most subsamples, implying that on average clothing is a luxury good (see also Banks et al., 1997, Bargain and Donni, 2009 for a similar result). Coefficients are significant in most cases. The coefficient of the Wu-Hausman residual is negative and significant in all subsamples, except for single females and for male clothing in childless couples. This suggests that endogeneity of expenditure is an issue so that this residual must also be included in the structural Engel curve estimations.

In what follows, we report and discuss the main estimates of our structural model based on $K-1=8$ household Engel curves. Our general specification contains 202 parameters (out of which 98 are significantly different from zero at least at the $10 \%$ level). While the complete estimates are available from the authors, we focus on scaling factors, interpreted as economies of scale, and on resources shares for adults and children.

\subsection{Economies of Scale}

The estimates of the scaling factors $s_{i, n}(\boldsymbol{z})$ are shown in the left panel of Table 2 . We first recall that the terms representing scale economies for children are normalized to 1 . If the scales for adults are to be interpreted as reflecting joint consumption, they should in principle lie between $\eta_{i, n}(\boldsymbol{z})$ (complete jointness of consumption) and 1 (purely private consumption) for a childless couple. In this respect, the estimates are reasonable in magnitude, especially given that we have not restricted the size of the coefficients in any way. The fact that these scales are much lower than 1 also underlines the possible existence of sizeable economies of scale in the household, which invalidates the traditional Rothbarth approach. For instance, a scale of 0.597 for a woman with a child suggests that her cost of living is $59.7 \%$ of the cost she would experience if living alone. We nonetheless remain cautious with this reading, given the broader interpretation of these scales suggested in section 2. Moreover, the magnitudes of the deflators

\footnotetext{
${ }^{17}$ Instead of total expenditure for couples without children to increase by a factor of 2 (when using the average expenditures of single men and women), it increases by a factor of 1.4, implying $33 \%$ savings derived from sharing. This result is also consistent with Lazear and Michael (1980) who find that expenditures of two adults living together are $30-35 \%$ lower than combined expenditure for two single-adult households (US data).
} 
Table 2: Estimated economies of scale

\begin{tabular}{lcccccccc}
\hline \hline & \multicolumn{4}{c}{ Scaling factors } & \multicolumn{5}{c}{ Normalized scaling factors } \\
\cline { 2 - 8 } & no children & 1 child & 2 children & 3 children & no children & 1 child & 2 children & 3 children \\
\hline \multirow{2}{*}{ women } & 0.457 & 0.597 & 0.510 & 0.449 & 1.794 & 1.372 & 1.514 & 1.607 \\
& $(0.591)$ & $(0.805)$ & $(0.701)$ & $(0.707)$ & $(1.894)$ & $(1.251)$ & $(1.455)$ & $(1.760)$ \\
\multirow{4}{*}{ men } & 0.827 & 0.881 & 0.820 & 0.687 & 1.312 & 1.153 & 1.240 & 1.447 \\
& $(0.405)$ & $(0.429)$ & $(0.415)$ & $(0.384)$ & $(0.887)$ & $(0.626)$ & $(0.674)$ & $(0.800)$ \\
\hline
\end{tabular}

Baseline model estimated on 9 goods (one residual: housing costs). Scaling factors are calculated for representative household, but estimates change very little with education or being urban/rural.

for different household types cannot be compared directly, since household members consume only a fraction of total expenditure. Hence, the right panel reports the normalized scaling factors $\sigma_{i, n}(\boldsymbol{z})$, as previously defined. They amount to 1.31 (resp. 1.79) for a man (resp. woman) living in a couple without children (recall that in the limit case, $\sigma_{i, n}(\boldsymbol{z})=2$, all the goods purchased by spouses can be considered as public consumption). ${ }^{18}$ One may expect economies of scale to increase in families with children compared to childless couples. Yet this may not always be the case if children bias consumption patterns towards more "privateness". ${ }^{19}$ The total effect is undetermined and remains an empirical question. Point estimates show a sharp decrease in scale economies with the first child, suggesting that there is less sharing of goods consumed by adults in this household type. They increase regularly with additional children, indicating economies of scale in larger families. Women seem to gain more than men from joint consumption. However, estimates are very imprecise and differences between household types are not significant.

\subsection{Resource Shares and Poverty}

We compute resource shares $\eta_{i, n}(\boldsymbol{z})$ for all the individuals in our sample and report statistics for different sub-groups. Table 3 summarizes the results while Table A.1 in the Appendix reports the mean shares for men, women and children in detailed demographic groups and according to parents' education levels. Note that estimations of resource shares are in general much more precise than that of scaling factors. Results indicate slightly larger share for men on average.

\footnotetext{
${ }^{18}$ Joint consumption among households is certainly important. On Canadian data, Browning et al. (2008) obtain economies of scale, aggregated over the household using a different methodology, which are in the same order of magnitude (i.e., between 1.27 and 1.41). On US data, Nelson (1989) finds even larger economies of scale.

${ }^{19}$ For goods with a high public component, like housing, economies of scale may partly disappear as the family decides to move to a bigger house to accommodate an additional child. For private goods, we have discussed above the fact that food shares increase with the presence of children (who are more food intensive than adults), which may overall result in an increase in the relative level of private consumption in the household.
} 
We observe a more balanced division of resources when women are educated and men are not (Table A.1). The difference between spouses is however not statistically significant. ${ }^{20}$ To our knowledge, existing evidence based on the estimation of collective models is limited to developed countries. For instance, the average wife's shares, as estimated by Browning et al. (2008) on Canadian data and by Bargain and Donni (2009) on French data, are in excess of 0.60. An exception is Dunbar et al. (2010) who find larger shares for men in couples with several children in Malawi - they also find that the absolute share of husbands increases in families of several children compared to one-child families, in the spirit of Duflo (2003).

The resource share of children seems reasonable and increases in a plausible way with household size (recall that we have not imposed any regularity in the sharing function in that respect). The per capita shares become smaller with the number of children, as in Dunbar et al. (2010). Mean shares are around $12.6 \%$ (first child), $8.3 \%$ (second child) and $6.8 \%$ (third child). Table A.1 indicates that boys receive more than girls, yet the difference is not significant. Hence, our results are in line with Deaton (1989) who found no evidence of child gender bias in the overall treatment of boys and girls in Côte d'Ivoire, using adult equivalence outlay ratios and data for the year 1985. Deaton (1997) suggests that the absence of child gender bias may be due to the fact that women in West Africa are economically productive and girls are not seen as a burden in their parents, while Haddad et al. (1994) explains this from a cultural perspective. ${ }^{21}$ Point estimates show that children receive higher shares when the mother is the educated adult, yet this trend is not statistically significant.

Estimated shares give us a sense of who get how much in the household. Yet it does not tell us if resource allocations are premised on the corresponding needs of each individual or reflect inequality in terms of welfare. Hence, we take a step further and examine the implications of these allocations on the poverty of the different household members. To this end, we use the computed resource shares accruing to each individual in the household to construct the actual expenditure for a given individual. We use the World Bank's poverty line set at US $\$ 2$ per day to identify poor adults. As in Dunbar et al. (2010), we use a US\$1.20 per day poverty line for children, which means that children's needs are $60 \%$ that of adults (as in the modified OECD equivalence scale). The poverty levels arising therefrom are labeled "unequal" in Table 3 while poverty based on per capita expenditure, i.e., a standard measure ignoring intra-household inequality, is reported under the "equal" label. Overall we find that poverty increases with household size when using

\footnotetext{
${ }^{20}$ Further research should incorporate distribution factors like differences between spouses in terms of exogenous income, which may influence the overall structure of consumption and female and child shares. For instance, Thomas (1990) note that unearned income in the hands of the mother has a bigger effect on child health.

${ }^{21}$ They suggest that parents are reluctant to discriminate against daughters due to the practice of bride-wealth in which parents of a bride receive payment as a compensation for the loss of a valuable worker.
} 
the usual per capita measure, from $21.8 \%$ of childless households to $50.4 \%$ of households with three children (for a comparison, the World Bank reported a general poverty rate of $42 \%$ in 2002). When using the "unequal" measure, however, adult poverty rates are smaller and do not change much across household types, which reflects the fact that their resource shares do not decrease proportionally with the number of people in the household. In contrast, resources in larger households are skewed in favor of adults rather than children. As indicated above, per capita expenditure for children decreases with the number of children. As the per capita measure over-estimates poverty levels for adults, it also severely under-estimates poverty among children. Dunbar et al. (2010) point to very similar results in Malawi. Admittedly, poverty levels depend on the assumption concerning the relative needs of each household member. We have used the modified OECD scale for an illustration, yet child poverty remains greatly understated unless one is ready to assume very small needs for children. ${ }^{22}$ In fact, for child poverty to equalize adult poverty, children's need should be as little as $30 \%, 25 \%$ and $17 \%$ of adult needs in couples with one, two and three children respectively. If these levels are deemed implausible, this indicates a certain extent of intrahousehold inequality.

Finally, the poverty rates of single women (men) is around $10 \%$ (15\%), i.e., much smaller than that of adults living with ohers. When joint consumption is accounted for, however, poverty rates of adults in couples go down very substantially. This can be seen in the last column of Table 3, which reports an "unequal, adjusted" measure of poverty for adults, i.e., based on individual shares and accounting for the gains due to joint consumption. For instance, in couples with two children, individual poverty rates are $29.2 \%$ (24.5\%) for women (men) according to the "unequal" measure. They decline to $9.5 \%(15.8 \%)$ after accounting for economies of scale. In all cases, the reduction in poverty levels is higher for women, which reflects previous differences in scale economies between men and women. This pattern is consistent across all types of households and shows (with the reservation that standard errors of scaling factors are large) that for all types, poverty rates of adults living in a family are of the same order as that of single individuals. That is, for adults, joint consumption tends to compensate the fact that people must share resources.

\section{Additional Results}

\subsection{Comparison with Dunbar et al. (2010)'s study}

At this stage, it may be interesting to make a comparison with the method suggested by Dunbar et al. (2010), already mentioned in the introduction. Both studies rely to some extent on

\footnotetext{
${ }^{22}$ If we assume that children needs are only $30 \%$ that of adults, their poverty rates go down to $25 \%, 40 \%$ and $59 \%$ in couples with one, two and three children respectively.
} 
Table 3: Poverty rates

\begin{tabular}{|c|c|c|c|c|c|c|c|c|c|}
\hline & & \multicolumn{5}{|c|}{ Resource shares } & \multicolumn{3}{|c|}{ Poverty rates } \\
\hline & & mean & std. dev. & $\min$. & med. & $\max$ & Equal & Unequal & $\begin{array}{l}\text { Unequal, } \\
\text { adjusted }\end{array}$ \\
\hline \multirow[t]{2}{*}{ Couple with no child } & woman & 0.478 & 0.051 & 0.386 & 0.487 & 0.586 & 0.218 & 0.224 & 0.051 \\
\hline & $\operatorname{man}$ & 0.522 & 0.051 & 0.414 & 0.513 & 0.614 & & 0.218 & 0.122 \\
\hline \multirow[t]{4}{*}{ Couple with one child } & woman & 0.411 & 0.038 & 0.342 & 0.422 & 0.490 & 0.329 & 0.281 & 0.146 \\
\hline & $\operatorname{man}$ & 0.463 & 0.050 & 0.367 & 0.447 & 0.553 & & 0.245 & 0.179 \\
\hline & children & 0.126 & 0.013 & 0.100 & 0.126 & 0.161 & & 0.715 & \\
\hline & each child & 0.126 & 0.013 & 0.100 & 0.126 & 0.161 & & & \\
\hline \multirow[t]{4}{*}{ Couples with two children } & woman & 0.402 & 0.036 & 0.331 & 0.414 & 0.470 & 0.442 & 0.292 & 0.095 \\
\hline & $\operatorname{man}$ & 0.432 & 0.053 & 0.315 & 0.420 & 0.533 & & 0.247 & 0.158 \\
\hline & two children & 0.165 & 0.020 & 0.129 & 0.165 & 0.228 & & 0.877 & \\
\hline & each child & 0.083 & 0.010 & 0.065 & 0.083 & 0.114 & & & \\
\hline \multirow[t]{4}{*}{ Couples with three children } & woman & 0.387 & 0.032 & 0.321 & 0.398 & 0.442 & 0.504 & 0.263 & 0.085 \\
\hline & $\operatorname{man}$ & 0.408 & 0.049 & 0.325 & 0.392 & 0.508 & & 0.224 & 0.108 \\
\hline & three children & 0.205 & 0.017 & 0.171 & 0.210 & 0.235 & & 0.909 & \\
\hline & each child & 0.068 & 0.006 & 0.057 & 0.070 & 0.078 & & & \\
\hline
\end{tabular}

Note: shares are calculated for each individual and we report statistics for each demographic group. For poverty rates, we use the $\$ 2$ per day poverty line for an adult, as suggested by the World Bank, and US $\$ 1.20$ per day for a child. "Equal" poverty rates are obtained using per capita expenditure. "Unequal" poverty rates are obtained using the share of expenditure that each individual receives in the household. "Unequal, adjusted" accounts for the scale economies in couples. For the latter, note that for a comparison, the poverty rate of single men (women) is $14.9 \%(10.0 \%)$.

the stability of individual preferences across household types and on adult clothing to identify children's share. The identification result of Dunbar et al. (2010) also exploits child goods, which is not necessary in our case, even if it may improve the precision of the results. Another difference is the fact that we are using information on single individuals while their approach simply relies on couples. Our approach is, in a sense, more restrictive since we assume preference stability across more household types and, notably, between individuals alone and in a family. Nevertheless, Dunbar et al. (2010) are incited to make assumptions on the stability of preferences across people living in the household to obtain precise results, and some of their identification relies on parametric forms. Finally, our approach allows recovering economies of scale and indifference curves. The latter are required to compare the living standard of singles and persons in couple (with children or not). Unsurprisingly, our approach uses more structure so that it is possible to recover more elements of the decision process.

The principal objective of both studies is to retrieve resource shares for the most vulnerable family members, i.e., children. Hence, it is important to check that the two approaches do not lead to completely different results in this respect. Comparison is made in the first columns of 
Table 4. Even though the empirical approaches and the countries are different, the children's shares are relatively close. For couples with one, two and three children, shares per child are 13.5 (12.6), 10.5 (8.3) and 7.9 (6.8) in their (our) case. Inequality between spouses is also similar for childless couples - but contrasted for larger families. That is, we find that both parents contribute to children expenditure while results for Malawi show that the cost of children is essentially born by mothers (fathers' share even increase with family size). The similarity of results concerning children's shares is not surprising - and surely reassuring - given that the two studies use the same fundamental principle to recover them, i.e., the Rothbarth idea of measuring how the consumption of adult goods vary across different household types.

\subsection{Other Models}

We finally suggest alternative empirical strategies, relying on the same fundamental identifying principle. The objective is to extend the comparison with Dunbar et al. (2010) and to consolidate the general method based on adult clothing. We check especially if the measure of children's share is not too sensitive to the other assumptions made on top of the Rothbarth's principle (and in particular the way flexibility is introduced in the Rothbarth model).

Model without Information on Singles. We start with a model which is closer to that of Dunbar et al. (2010) in the sense that we now restrict our estimations to observations on couples only, using expenditure on adult clothing, child clothing and a residual (corresponding to other household expenditures). The parents are treated as a unitary couple, so that we focus only on sharing between parents and children. ${ }^{23}$ Childless couples now serve as the reference group (couples with one child in the case of Dunbar et al., 2010). That is, for this group $n=2$, we suppose that there exists a well-behaved indirect utility function $v_{a}\left(x, \boldsymbol{p}, \boldsymbol{z}_{a}\right)$, where index $a$ stands for 'adults'. Since the notion of assignability is rather meaningless in the present context, we now model the budget shares for both adults' together (e.g., total adult clothing). Denote $k_{a}$ the adult-specific goods, the household budget share for that good in a childless couple is:

$$
W_{2}^{k_{a}}(x, \boldsymbol{z})=w_{a}^{k_{a}}\left(x, \boldsymbol{z}_{a}\right),
$$

so the basic budget shares of parents are identified on childless couples (and not on singles, as we did previously in step 1). For adult specific goods $k_{a}$, the household budget shares in couples with children are:

$$
W_{3}^{k_{a}}(x, \boldsymbol{z})=\eta_{a, 3}(\boldsymbol{z}) \cdot\left[\lambda_{a, 3}^{k_{a}}(\boldsymbol{z})+w_{a}^{k_{a}}\left(x+\log \eta_{a, 3}(\boldsymbol{z})-\log s_{a, 3}(\boldsymbol{z}), \boldsymbol{z}_{a}\right)\right] .
$$

\footnotetext{
${ }^{23}$ This is more parsimonious than in the other approaches, but not really costly in terms of realism. Indeed, in the absence of prices and distribution factors in the sharing rule, unitary models cannot be empirically distinguished from collective ones.
} 
Table 4: Resource Shares: Estimates from Alternative Models

\begin{tabular}{|c|c|c|c|c|c|c|c|c|c|c|c|c|c|c|c|c|}
\hline & \multicolumn{4}{|c|}{$\begin{array}{l}\text { Baseline model } \\
\text { (I) }\end{array}$} & \multicolumn{4}{|c|}{$\begin{array}{l}\text { Dunbar et al. (2010) } \\
\text { (II) }\end{array}$} & \multicolumn{4}{|c|}{$\begin{array}{c}\text { Model with "unitary" parents } \\
\text { (III) }\end{array}$} & \multicolumn{4}{|c|}{$\begin{array}{c}\text { Gronau-Rothbarth model } \\
\text { (IV) }\end{array}$} \\
\hline \multicolumn{17}{|l|}{ Model specification } \\
\hline \# goods (incl. residual) & \multicolumn{4}{|c|}{9} & \multicolumn{4}{|c|}{4} & \multicolumn{4}{|c|}{3} & \multicolumn{4}{|c|}{3} \\
\hline identifying information* & \multicolumn{4}{|c|}{ adult clothing, singles } & \multicolumn{4}{|c|}{$\begin{array}{l}\text { assignable clothing (man, } \\
\text { woman, children) }\end{array}$} & \multicolumn{4}{|c|}{ adult clothing } & \multicolumn{4}{|c|}{ adult clothing } \\
\hline household types** & \multicolumn{4}{|c|}{$\mathbf{S}, \mathrm{C} 0, \mathrm{C} 1-3$} & \multicolumn{4}{|c|}{ C1, C2-4 } & \multicolumn{4}{|c|}{$\mathrm{C} 0, \mathrm{C} 1-3$} & \multicolumn{4}{|c|}{ C0, C1-3 } \\
\hline \multicolumn{17}{|l|}{ Identification of: } \\
\hline adults' scaling factors & \multicolumn{4}{|c|}{ Yes } & \multicolumn{4}{|c|}{ No } & \multicolumn{4}{|c|}{ Yes } & \multicolumn{4}{|c|}{ No } \\
\hline sharing among adults & \multicolumn{4}{|c|}{ Yes } & \multicolumn{4}{|c|}{ Yes } & \multicolumn{4}{|c|}{ No } & \multicolumn{4}{|c|}{ No } \\
\hline Resource shares & Mean & $\begin{array}{l}\text { std. } \\
\text { dev }\end{array}$ & Min & Max & Mean & $\begin{array}{l}\text { std. } \\
\text { dev }\end{array}$ & Min & Max & Mean & $\begin{array}{l}\text { std. } \\
\text { dev }\end{array}$ & Min & $\operatorname{Max}$ & Mean & $\begin{array}{l}\text { std. } \\
\text { dev }\end{array}$ & Min & $\operatorname{Max}$ \\
\hline \multicolumn{17}{|l|}{ Couple with one child } \\
\hline adults & 0.874 & 0.044 & 0.355 & 0.521 & 0.865 & 0.079 & 0.207 & 0.675 & 0.841 & 0.044 & 0.735 & 0.938 & 0.886 & 0.063 & 0.341 & 0.561 \\
\hline woman & 0.411 & 0.038 & 0.342 & 0.490 & 0.402 & 0.071 & 0.168 & 0.587 & 0.420 & 0.022 & 0.367 & 0.422 & 0.365 & 0.054 & 0.276 & 0.470 \\
\hline man & 0.463 & 0.050 & 0.367 & 0.553 & 0.463 & 0.087 & 0.245 & 0.762 & 0.420 & 0.022 & 0.367 & 0.469 & 0.522 & 0.071 & 0.406 & 0.652 \\
\hline children & 0.126 & 0.013 & 0.100 & 0.161 & 0.135 & 0.047 & 0.008 & 0.260 & 0.159 & 0.044 & 0.062 & 0.265 & 0.113 & 0.022 & 0.061 & 0.165 \\
\hline each child & 0.126 & 0.013 & 0.100 & 0.161 & 0.135 & 0.047 & 0.008 & 0.260 & 0.159 & 0.044 & 0.062 & 0.265 & 0.113 & 0.022 & 0.061 & 0.165 \\
\hline Couple with two children & & & & & & & & & & & & & & & & \\
\hline adults & 0.835 & 0.045 & 0.323 & 0.501 & 0.789 & 0.071 & 0.179 & 0.631 & 0.830 & 0.043 & 0.735 & 0.905 & 0.859 & 0.062 & 0.319 & 0.545 \\
\hline woman & 0.402 & 0.036 & 0.331 & 0.470 & 0.273 & 0.063 & 0.075 & 0.475 & 0.415 & 0.021 & 0.368 & 0.452 & 0.363 & 0.052 & 0.259 & 0.458 \\
\hline $\operatorname{man}$ & 0.432 & 0.053 & 0.315 & 0.533 & 0.516 & 0.078 & 0.282 & 0.786 & 0.415 & 0.021 & 0.368 & 0.452 & 0.496 & 0.072 & 0.380 & 0.633 \\
\hline two children & 0.165 & 0.020 & 0.129 & 0.228 & 0.211 & 0.044 & 0.059 & 0.326 & 0.170 & 0.043 & 0.095 & 0.265 & 0.140 & 0.021 & 0.096 & 0.182 \\
\hline each child & 0.083 & 0.010 & 0.065 & 0.114 & 0.105 & 0.022 & 0.029 & 0.163 & 0.085 & 0.021 & 0.048 & 0.132 & 0.070 & 0.010 & 0.048 & 0.091 \\
\hline Couple with three children & & & & & & & & & & & & & & & & \\
\hline adults & 0.795 & 0.040 & 0.323 & 0.475 & 0.765 & 0.073 & 0.111 & 0.654 & 0.811 & 0.035 & 0.737 & 0.877 & 0.837 & 0.059 & 0.321 & 0.521 \\
\hline woman & 0.387 & 0.032 & 0.321 & 0.442 & 0.244 & 0.065 & 0.002 & 0.512 & 0.405 & 0.018 & 0.368 & 0.438 & 0.357 & 0.047 & 0.265 & 0.434 \\
\hline $\operatorname{man}$ & 0.408 & 0.049 & 0.325 & 0.508 & 0.521 & 0.081 & 0.219 & 0.795 & 0.405 & 0.018 & 0.368 & 0.438 & 0.480 & 0.070 & 0.377 & 0.609 \\
\hline three children & 0.205 & 0.017 & 0.171 & 0.235 & 0.236 & 0.042 & 0.112 & 0.374 & 0.189 & 0.035 & 0.123 & 0.263 & 0.162 & 0.024 & 0.103 & 0.205 \\
\hline each child & 0.068 & 0.006 & 0.070 & 0.078 & 0.079 & 0.014 & 0.037 & 0.125 & 0.063 & 0.012 & 0.041 & 0.088 & 0.054 & 0.008 & 0.034 & 0.068 \\
\hline
\end{tabular}

The identification is basically the same as in Proposition 1, except that parents' basic share are now recovered from childless couples.

Traditional Rothbarth Model. As in the previous model, we suppose that the chosen reference demographic group is childless couples. Then we ignore scale economies, i.e., assume $\lambda_{a, 3}^{k_{a}}=\log s_{a, 3}=0$. The household budget share for the adult good $k_{a}$ is:

$$
W_{3}^{k_{a}}(x, \boldsymbol{z})=\eta_{a, 3}(\boldsymbol{z}) \cdot\left[w_{a}^{k_{a}}\left(x+\log \eta_{a, 3}(\boldsymbol{z}), \boldsymbol{z}_{a}\right)\right] .
$$

This model is essentially the traditional Rothbarth approach using childless couples to retrieve parents' basic budget shares. Alternatively, it would be possible to use singles for that purpose, 
as in our baseline model or in Gronau (1991). We stick to the chosen specification so that the Rothbarth model is nested in the "unitary" parent model.

Results. These two models, estimated on data for couples only, show interesting results, as reported in the last columns of Table 4. The first model with "unitary" parents yields larger shares for the first child compared to our baseline model (and similar results for other groups). This may be related to the fact that these variants only rely on Engel curves for clothing expenditures, or on the fact that childless couples are now use as reference group for normalizing scale economies. ${ }^{24}$ With the version of the Rothbarth's model suggested here, children's shares are smaller for all household types. This can be interpreted as parents having larger shares because they are not implicitly compensated by scale economies as in other models (see the similar result on French data, and the related discussion, in Bargain and Donni, 2009). Overall, the estimations of children's shares are of the same order of magnitude.

\section{Conclusion}

In this paper, we suggest an estimation of the share of household resources accruing to children in Côte d'Ivoire. Generalizing the conventional Rothbarth method, the approach is consistent with the existence of economies of scale and parental bargaining in a structural, multi-person model. Importantly, this contribution completes the literature on collective models, which usually ignore children and have been essentially applied on data from developed countries. The model is simply estimated on the basis of Engel curves for typical aggregated commodities including adult-specific goods (clothing). Identification is obtained for three types of people (men, women, and children) in more than three types of households (single men, single women, couples with zero, one, two or three children). The presence of adult goods in these household types permits identification of children's shares even though children are never observed living alone. Empirical results for Côte d'Ivoire show that scaling factors, interpreted as economies of scale in multi-person households, turn out to be very large but imprecisely estimated. Parents' expenditures made for children living in the household range between $13 \%$ and a fifth of total resources for couples with one to three children respectively. Poverty calculations suggest that ignoring intra-household distribution of resources leads to a large underestimation of child poverty when using reasonable differentiation in individual needs across household members.

\footnotetext{
${ }^{24}$ In results that are not reported, we find that estimations are very close to those of the model without information on singles when male and female clothing expenditures are used separately. This indicates that using assignable goods for men and women respectively, and using this information to recover the share of each adult, has no impact on our measure of children's share.
} 
Interestingly, our results on the resource share of children are very similar to that obtained under different identifying assumptions, and notably when using only assignable goods and observations for couples. Imposing restrictions ("unitary" parents, no scale economies) also lead to similar results. In fact, all these variants rely on the same fundamental identifying strategy, the Rothbarth idea, and help to consolidate the overall approach once additional flexibility is incorporated.

Two limitations of the present paper could inspire further research. First, resource shares could be made dependent of total expenditures given data and models for multiple price regimes. Alternatively, they could depend on another measure of household wealth. This is important to retrieve how children's shares vary with household total resources and the consequences on child poverty. Second, a contribution of the present paper was to introduce more flexibility, in the form of terms accounting for publicness in consumption, in a Rothbarth approach using singles as the reference group for adults. However, as extensively discussed in the core of the paper, scaling factors may also capture consumption externalities or changes in individual preferences across household types. A lot remains to be done to disentangle these different interpretations. 


\section{Appendix}

\begin{tabular}{|c|c|c|c|c|c|c|c|c|c|c|c|}
\hline & & $\begin{array}{c}\text { no } \\
\text { children }\end{array}$ & 1 boy & 1 girl & 2 girls & 2 boys & $\begin{array}{c}1 \text { boy } \& 1 \\
\text { girl }\end{array}$ & 3 boys & 3 girls & $\begin{array}{c}2 \text { boys } \& \\
1 \text { girl }\end{array}$ & $\begin{array}{l}2 \text { girls \& } 1 \\
\text { boy }\end{array}$ \\
\hline \multirow{6}{*}{ Woman } & \multirow[t]{2}{*}{ Average } & 0.4783 & 0.4081 & 0.4143 & 0.4050 & 0.3990 & 0.4024 & 0.3884 & 0.3857 & 0.3891 & 0.3860 \\
\hline & & $(0.051)$ & $(0.037)$ & $(0.040)$ & $(0.035)$ & $(0.037)$ & $(0.036)$ & $(0.034)$ & $(0.028)$ & $(0.032)$ & $(0.032)$ \\
\hline & \multirow{2}{*}{$\begin{array}{l}\text { Educated woman, } \\
\text { uneducated man }\end{array}$} & 0.4907 & 0.4126 & 0.4270 & 0.4146 & 0.4245 & 0.4190 & 0.3836 & 0.3882 & 0.4021 & 0.4007 \\
\hline & & $(0.055)$ & $(0.039)$ & $(0.040)$ & $(0.041)$ & $(0.035)$ & $(0.036)$ & $(0.030)$ & $(0.035)$ & $(0.035)$ & $(0.035)$ \\
\hline & \multirow{2}{*}{$\begin{array}{l}\text { Uneducated woman, } \\
\text { educated man }\end{array}$} & 0.4753 & 0.4086 & 0.4118 & 0.4041 & 0.3977 & 0.4010 & 0.3979 & 0.3950 & 0.3896 & 0.3865 \\
\hline & & $(0.055)$ & $(0.039)$ & $(0.041)$ & $(0.037)$ & $(0.035)$ & $(0.036)$ & $(0.029)$ & $(0.027)$ & $(0.032)$ & $(0.034)$ \\
\hline \multirow{6}{*}{ Man } & \multirow[t]{2}{*}{ Average } & 0.5217 & 0.4598 & 0.4652 & 0.4311 & 0.4350 & 0.4316 & 0.4048 & 0.4124 & 0.4046 & 0.4106 \\
\hline & & $(0.051)$ & $(0.037)$ & $(0.052)$ & $(0.051)$ & $(0.055)$ & $(0.053)$ & $(0.052)$ & $(0.043)$ & $(0.048)$ & $(0.050)$ \\
\hline & \multirow{2}{*}{$\begin{array}{l}\text { Educated woman, } \\
\text { uneducated man }\end{array}$} & 0.5093 & 0.4543 & 0.4493 & 0.4182 & 0.4015 & 0.4095 & 0.4122 & 0.4079 & 0.3849 & 0.3887 \\
\hline & & $(0.055)$ & $(0.052)$ & $(0.052)$ & $(0.061)$ & $(0.054)$ & $(0.051)$ & $(0.045)$ & $(0.055)$ & $(0.054)$ & $(0.053)$ \\
\hline & \multirow{2}{*}{$\begin{array}{l}\text { Uneducated woman, } \\
\text { educated man }\end{array}$} & 0.5247 & 0.4594 & 0.4683 & 0.4337 & 0.4382 & 0.4348 & 0.3902 & 0.3990 & 0.4044 & 0.4098 \\
\hline & & $(0.055)$ & $(0.052)$ & $(0.053)$ & $(0.051)$ & $(0.051)$ & $(0.053)$ & $(0.045)$ & $(0.041)$ & $(0.049)$ & $(0.052)$ \\
\hline \multirow{6}{*}{ Children } & \multirow[t]{2}{*}{ Average } & & 0.1321 & 0.1206 & 0.1639 & 0.1659 & 0.1660 & 0.2068 & 0.2019 & 0.2063 & 0.2034 \\
\hline & & & $(0.013)$ & $(0.012)$ & $(0.018)$ & $(0.022)$ & $(0.020)$ & $(0.018)$ & $(0.015)$ & $(0.017)$ & $(0.017)$ \\
\hline & \multirow{2}{*}{$\begin{array}{l}\text { Educated woman, } \\
\text { uneducated man }\end{array}$} & & 0.1331 & 0.1237 & 0.1673 & 0.1739 & 0.1714 & 0.2042 & 0.2039 & 0.2130 & 0.2107 \\
\hline & & & $(0.013)$ & $(0.012)$ & $(0.021)$ & $(0.021)$ & $(0.019)$ & $(0.015)$ & $(0.019)$ & $(0.019)$ & $(0.018)$ \\
\hline & \multirow{2}{*}{$\begin{array}{l}\text { Uneducated woman, } \\
\text { educated man }\end{array}$} & & 0.1320 & 0.1199 & 0.1622 & 0.1642 & 0.1642 & 0.2118 & 0.2060 & 0.2060 & 0.2037 \\
\hline & & & $(0.013)$ & $(0.012)$ & $(0.017)$ & $(0.019)$ & $(0.019)$ & $(0.016)$ & $(0.014)$ & $(0.017)$ & $(0.018)$ \\
\hline
\end{tabular}

Table A.1.: Shares of Total Expenditure in Couple Households

\section{References}

[1] Banks, J., Blundell, R. W., Lewbel, A. (1997): "Quadratic Engel curves and consumer demand", Review of Economics and Statistics 79(4), 527-539.

[2] Bargain, O. and O. Donni (2009): "The Measurement of Child Costs: A Rothbarth-Type Method Consistent with Scale Economies", IZA Discussion Paper No. 4654.

[3] Bhalotra, S. and C. Attfield (1998): "Intrahousehold resource allocation in rural Pakistan: a semiparametrical analysis", Journal of Applied Econometrics 13(5), 463-480

[4] Blackorby, C. and D. Donaldson. (1993), "Adult-equivalence scales and the economic implementation of interpersonal comparisons of well-being", Social Choice and Welfare, 10, 335361 .

[5] Blundell, R. W. and A. Lewbel (1991), "The Information Content of Equivalence Scales", Journal of Econometrics, 50, 49-68. 
[6] Blundell, R., P.-A. Chiappori and C. Meghir (2005): "Collective labor supply with children", Journal of Political Economy, 113 (6), 1277-1306

[7] Bourguignon, F. (1999): "The cost of children: May the collective approach to household behaviour help?" Journal of Population Economics 12 (4), 503-522

[8] Bourguignon, F., M. Browning and P-A. Chiappori (2009), "Efficient Intra-Household Allocations and Distribution Factors: Implications and Identification", Review of Economics Studies, 76, 503-528.

[9] Browning, M. (1992), "Children and Household Economic Behavior", Journal of Economic Literature, 30, 1434-1475.

[10] Browning, M. and P.A. Chiappori (1998): "Efficient Intra-household Allocations: A General Characterization and Empirical Tests", Econometrica, 66, 1241-1278.

[11] Browning, M., F. Bourguignon, P.A. Chiappori and V. Lechene (1994): "Income and Outcomes: A Structural Model of Intrahousehold Allocation," Journal of Political Economy, $102,1067-1096$.

[12] Browning, M., P-A. Chiappori and A. Lewbel (2008), "Estimating Consumption Economies of Scale, Adult Equivalence Scales, and Household Bargaining Power", Working Paper, Boston College.

[13] Chiappori, P.A. (1988): "Rational household labor supply", Econometrica, 56, 63-89.

[14] Chiappori, P-A. and O. Donni (2011), "Non-Unitary Models of Household Behavior: A Survey of the Literature". In: A. Molina (eds), Household Economic Behaviors, Berlin: Springer.

[15] Couprie, H. (2007): "Time Allocation within the Family: Welfare Implication of Life in Couple", Economic Journal, 117, 287-30

[16] Dauphin, A., A-R. El Lahga, B. Fortin and G. Lacroix (2011): "Are Children DecisionMakers Within the Household?", Economic Journal, 121, 871-903.

[17] Deaton, A. (1989): "Looking for Boy-Girl Discrimination in Household Expenditure Data", World Bank Economic Review, 3(1), 1-15

[18] Deaton, A. (1997), The Analysis of Household Surveys: A Microeconometric Approach to Development Policy, Baltimore: The John Hopkins University Press.

[19] Deaton, A. and C. Paxson (1998): "Economies of scale, household size, and the demand for food", Journal of Political Economy, 106(5), 897-930

[20] Duflo, E. (2003): "Grandmothers and Granddaughters: Old Age Pension and IntraHousehold Allocation in South Africa", World Bank Economic Review, 17(1), 1-25. 
[21] Duflo, E. and C. Udry (2004): "Intrahousehold Resource Allocation in Côte d'Ivoire: Social Norms, Separate Accounts and Consumption Choices", NBER Working Papers 10498, National Bureau of Economic Research, Inc.

[22] Dunbar G., A. Lewbel and K. Pendakur (2010): "Children's Resources in Collective Households: Identification, Estimation and an Application to Child Poverty in Malawi," Boston College Working Papers in Economics 758.

[23] Gronau, R. (1988), "Consumption Technology and the Intrafamily Distribution of Resources: Adult Equivalence Scales Reexamined", Journal of Political Economy, 96(6), 1183-1205.

[24] Gronau, R. (1991), "The Intrafamily Allocation of Goods - How to Separate the Adult from the Child", Journal of Labor Economics, 9(3), 207-235.

[25] Haddad. L. and R. Kanbur (1990): "How serious is the neglect of intra-household inequality?", Economic Journal, 100, 866-881.

[26] Haddad, L. J. Hoddinott and T. Lloyd (1994): "Household resource allocation in the Côte d'Ivoire: inferences from expenditure data", in T. Lloyd and O. Morrissey (eds), Poverty, Inequality and Rural Development, pp. 67-88.

[27] Haddad, L., and J. Hoddinott (1994): "Women's Income and Boy-Girl Anthropometric Status in the Côte d'Ivoire", World Development 22(4), 543-553.

[28] Hoddinott, J. and L. Haddad (1995): "Does female income share influence household expenditures? Evidence from Côte d'Ivoire", Oxford Bulletin of Economics and Statistics, $57(1)$

[29] Lazear, E.P. and R.T. Michael (1980): "Family size and the distribution of per capita income", American Economic Review, 70(1), 91-107.

[30] Lazear, E.P. and R.T. Michael (1988), Allocation of Income within the Household, Chicago: University of Chicago Press.

[31] Lewbel, A. (1991): "Cost of Characteristics Indices and Household Equivalence Scales", European Economic Review, 35, 1277-1293.

[32] Lewbel, A. (2003): "Calculating Compensation in Cases of Wrongful Death," Journal of Econometrics, 113, 115-128.

[33] Lewbel, A. and K. Pendakur (2008): "Estimation of Collective Household Models with Engel Curves", Journal of Econometrics, special issue on Estimating Demand Systems and Consumer Preferences, 147, 350-358.

[34] Lise, J. and S. Seitz (2011): "Consumption Inequality and Intra-Household Allocations," Review of Economic Studies, 78(1), 328-355. 
[35] Matzkin, R. L. (2007): "Nonparametric Identification", in: J. Heckman and E. Leamer (eds), Handbook of Econometrics, VI, Elsevier.

[36] Menon, M. and F. Perali (2007): "The cost of rearing children, child welfare and child poverty within the collective household model", mimeo

[37] Nelson, J. A. (1989): "Household Economies of Scale in Consumption: Theory and Evidence", Econometrica, 56, 1301-1314.

[38] Pendakur, K. (1999): "Estimates and Tests of Base-Independent Equivalence Scales", Journal of Econometrics, 88, 1-40

[39] Pollak, R. and T. J. Wales (1979): "Welfare Comparisons and Equivalence Scales", American Economic Review, 69, 216-221.

[40] Rangel, M.A. and D. Thomas (2005): "Out of West Africa: Evidence on the Efficient Allocation of Resources within Farm Households", University of Chicago

[41] Rothbarth, E. (1943): "Note on a method of determining equivalent income for families of different composition", in C. Madge (ed) War-time Pattern of Saving and Spending, Cambridge University Press, Cambridge.

[42] Rose, E. (1999): "Consumption Smoothing and Excess Female Mortality in Rural India," Review of Economics and Statistics, 81(1), 41-49.

[43] Thomas, D. (1990): "Intra-household Resource Allocation: An Inferential Approach", Journal of Human Resources, 25, 635-664.

[44] Udry,. C. and. H. Woo (2006): "Households and the Social Organization of Consumption in Southern Ghana", African Studies Review, 50, 2, 139-153

[45] Vernon, V (2005): "Food Expenditure, Food Preparation Time, and Household Economies of Scale", Fashion Institute of Technology, State University of New York. 